\title{
APRESENTACุÃO
}

\section{MÚLTIPLOS ENCONTROS: LINGUAGENS ESTUDOS LATINO-AMERICANOS}

\author{
Claudio Celso Alano da Cruz ${ }^{1}$ \\ Maria Graciela Eliggi ${ }^{2}$ \\ (Organizadores)
}

Há pouco mais de um ano, entre 9 e 12 de outubro de 2015, estivemos mais uma vez reunidos na bela capital chilena para participarmos do IV Congreso de la Internacional del Conocimiento - Ciencias, Tecnologías y Culturas. Mirando al futuro de América Latina y el Caribe, ao qual nos vinculamos desde a sua primeira realização, em 2008. Entre as dezenas e dezenas de simpósios que esse grande encontro acadêmico tem reunido a cada dois anos aproximadamente, sempre na sede da Universidade de Santiago de Chile (USACH), este volume buscou reunir uma parcela significativa dos trabalhos que foram apresentados e debatidos no âmbito do Simpósio de $n^{\circ} 6$ - Diálogos en el Conosur: viejas fronteras y nuevos espacios en literatura y cultura. No total foram aprovados para as apresentações orais 39 textos, oriundos dos mais variados lugares da América Latina, com a predominância, naturalmente, de investigadores vinculados a universidades da região do Conosur, e muito especialmente daquelas que os quatro coordenadores do Simpósio estão vinculados profissionalmente: Universidade Federal de Pelotas, Universidade Federal de Santa Catarina e Universidade Federal do Rio Grande do Sul, pelo lado brasileiro, e Universidade Nacional de La Pampa, pelo lado argentino. Além de várias outras destacadas universidades desses dois países, contamos também com a presença de pesquisadores representativos de universidades mexicanas, chilenas e colombianas. No intuito de agregar temáticas que envolvessem a

\footnotetext{
${ }^{1}$ Doutor em Teoria Literária pela Pontifícia Universidade Católica do Rio Grande do Sul (PUCRS), Professor Associado da Universidade Federal de Santa Catarina (UFSC) e Bolsista de Produtividade em Pesquisa do Conselho Nacional de Pesquisa Cientifica (CNPq). Realizou Pós-Doutoramento na Universidad de Buenos Aires (UBA)

${ }^{2}$ Magister en Literatura Angloamericana pela Universidad Nacional de Rio Cuarto- UNRC. Profesora Titular de Teoria Literaria en la Universidad Nacional de La Pampa - UNLPam.
} 


\section{Claudio Celso Alano da Cruz e Maria Graciela Eliggi}

Literatura Comparada, a História, e áreas do conhecimento relacionadas às Ciências Humanas, no contexto da América Latina, este Simpósio objetivou o diálogo com os diferentes profissionais, a partir da relação interdisciplinar que o tema propõe, ou seja: a alteridade, a transculturação, a mestiçagem, a identidade, o hibridismo cultural, as temporalidades. Levando-se em conta que as fronteiras entre o conhecimento, as nações e os povos aos poucos se abrem, não apenas geograficamente, mas de forma mais ampla, resultado da interpenetração das diversas áreas da produção científica, cujos reflexos podem ser notados nas formas de expressão do ser humano, buscou-se, neste Simpósio, refletir sobre tais processos. Portanto, como resultado final dessa rede de interação, recebemos, tal como se esperava a partir da chamada para o Simpósio, a contribuição de estudos sociológicos, antropológicos, geográficos, históricos e literários, entre outros, dando conta desse fenômeno, ou histórico, ou literário, ou científico, cada qual lançando mão de seus próprios recursos e de seu aparato teórico para a produção do conhecimento acadêmico. Uma amostra significativa dessas pesquisas apresentadas e debatidas durante a realização do nosso Simpósio poderão ser agora consultadas, seja pelos que dele participaram, muitas vezes com ricas e intensas discussões, seja pelos que não puderam estar presentes, mas gostariam de se inteirar do que lá foi debatido e exposto. São ao todo 15 textos, de variada temática, e todos eles elaborados por investigadores comprometidos com a ampliação e a divulgação do conhecimento acadêmico relativo à área de pesquisa a que cada um se encontra vinculado. Por fim, gostaríamos de agradecer a todos os que dividiram conosco estes dias de intensas trocas que vivemos em Santiago do Chile, e de modo muito especial aos autores dos textos que o leitor poderá ler a partir de agora. 